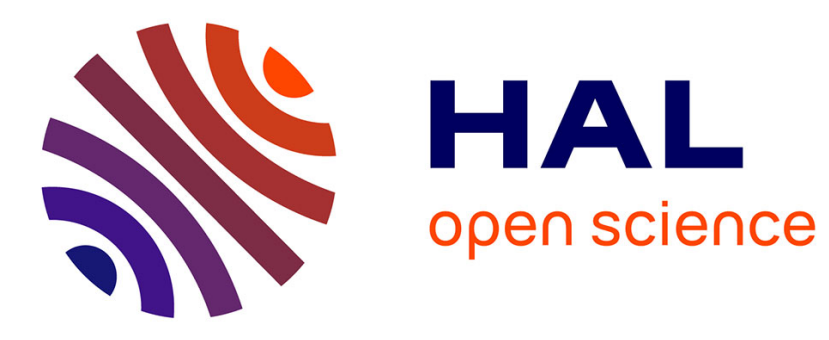

\title{
Recirculation cells in a wide channel
}

Hugo Chauvet, Olivier Devauchelle, François Métivier, Eric Lajeunesse, Angela Limare

\section{To cite this version:}

Hugo Chauvet, Olivier Devauchelle, François Métivier, Eric Lajeunesse, Angela Limare. Recirculation cells in a wide channel. Physics of Fluids, 2014, 26 (1), 17 p. 10.1063/1.4862442 . hal-01001919

\section{HAL Id: hal-01001919 \\ https://hal-univ-paris.archives-ouvertes.fr/hal-01001919}

Submitted on 5 Jun 2014

HAL is a multi-disciplinary open access archive for the deposit and dissemination of scientific research documents, whether they are published or not. The documents may come from teaching and research institutions in France or abroad, or from public or private research centers.
L'archive ouverte pluridisciplinaire HAL, est destinée au dépôt et à la diffusion de documents scientifiques de niveau recherche, publiés ou non, émanant des établissements d'enseignement et de recherche français ou étrangers, des laboratoires publics ou privés. 


\section{Recirculation cells in a wide channel}

H. ChaUVET, ${ }^{1, \text { a) }}$ O. DeVAuCHELle ${ }^{1}{ }^{1}$ F. METIVIER ${ }^{1}{ }^{1}$ E. LAJEUNESSE, ${ }^{1}$ and A. LIMARE $^{1}$

Laboratoire de dynamique des fluides géologiques, Institut de physique du globe de Paris (IPGP), Paris, FRANCE.

(Dated:)

Secondary flow cells are commonly observed in straight laboratory channels, where they are often associated with duct corners. Here, we present velocity measurements acquired with an Acoustic Doppler Current Profiler in a straight reach of the Seine river (France). We show that a remarkably regular series of stationary flow cells spans across the entire channel. They are arranged in pairs of counter-rotating vortices aligned with the primary flow. Their existence away from the river banks contradicts the usual interpretation of these secondary flow structures, which invokes the influence of boundaries. Based on these measurements, we use a depth-averaged model to evaluate the momentum transfer by these structures, and find that it is comparable with the classical turbulent transfer.

(Received 21 August 2013; accepted 19 December 2013; published online 23 January 2014) [http://dx.doi.org/10.1063/1.4862442]

a)Electronic mail: chauvet@ipgp.fr; http://www.ipgp.fr/ chauvet 


\section{INTRODUCTION}

Turbulent shear flows often generate stationary vortices aligned with the primary flow. They appear in rapid granular flows ${ }^{1}$, in Rayleigh-Bénard-Poiseuille flows ${ }^{2}$, in the superficial layers of sea and lakes ${ }^{3}$, in straight tubes ${ }^{4,5}$, as well as in straight channels and natural rivers $^{6-8}$.

In laboratory channels, a broad spectrum of instruments provide detailed measurements of the velocity field. They reveal secondary flow structures in the plane normal to the primary flow ${ }^{6,7,9,10}$, among which are the stationary helicoidal flows observed in straight channels (Prandtl refers to them as "secondary flow of the second kind"11). They were originally associated with duct corners ${ }^{10,12,13}$, where they were attributed to the turbulence anisotropy ${ }^{3,12,14-17}$. Recent experiments reported their existence in wide channels (aspect ratio of about 10), where they arrange themselves as pairs of counter-rotating vortices aligned with the stream direction ${ }^{6-8}$.

To our knowledge, secondary flow cells have never been measured in very wide channels - the only configuration which separates unambiguously recirculation cells from corner vortices. Alluvial rivers are typically wide and shallow, with an aspect ratio of a few tens ${ }^{18}$. Therefore, a significant proportion of their flow should be free from the influence of the banks. Nonetheless, various indirect observations such as sediment streaks ${ }^{10,19,20}$ or fluctuations in the suspended particles concentration ${ }^{21}$ have been associated to secondary flows in alluvial streams. There is however no clear consensus on the physical origin of these patterns $^{10,19,20}$.

To identify directly secondary flow cells in rivers, we need accurate measurements of the velocity field. Unfortunately, because they require heavy infrastructures, laboratory measurement techniques are of delicate use in the field. Instead, many river studies involve Acoustic Doppler Current Profilers (ADCP). An ADCP emits a diverging bunch of ultrasonic beams from a single source. The three-dimensional velocity field is then reconstructed from the measured radial velocities, thus making it possible to record velocity profiles with a light measurement setup. Due to the divergence of the beams, the velocity reconstruction relies on the assumption that the flow is uniform in the horizontal plane. This configurational limitation generally precludes ADCPs from measuring flow structures smaller than the water $\operatorname{depth}^{22}$. 
Recirculation cells, however, are still accessible to ADCP measurements, since they are streamwise invariant and stationary. Here we use these properties to identify recirculation cells in a straight reach of the Seine river (France). At this location, the river is wide and deprived of bed sediment, thus limiting the possible causes of recirculation. Based on these measurements, we then evaluate the momentum transfer by secondary flow cells, and compare it to the classical turbulent transfer.

\section{MEASUREMENTS}

\section{A. Acoustic Doppler Current Profiler}

Our ADCP (model RDI-Workhorse $1200 \mathrm{kHz}$ ) emits four divergent acoustic beams. Each beam measures the radial velocities $u_{r}$ every $25 \mathrm{~cm}$ through the water column. The beam angle with respect to the vertical direction is $\alpha=20^{\circ}$. Consequently, the distance $2 l_{\text {cor }}$ between opposite beams is proportional to the measurement depth $h$ :

$$
2 l_{\text {cor }}=2 h \tan (\alpha) \simeq 0.8 h \text {. }
$$

Used conventionally, an ADCP computes the Cartesian components of the velocity field $\left(u_{x}\right.$, $u_{y}$ and $u_{z}$ ) from the four radial velocities (figure $1 \mathrm{~b}$ ). For instance, to get the streamwise velocity $u_{x}$ at a depth $h$, it uses the radial velocities from beam 3 and beam 4 (figure $1 \mathrm{~b}$ ). The radial velocities $u_{r, 1}$ and $u_{r, 2}$ are decomposed as follows:

$$
\left(\begin{array}{l}
u_{r, 3} \\
u_{r, 4}
\end{array}\right)=\left(\begin{array}{cc}
u_{x, 3}\left(-l_{\text {cor }}\right) & u_{z, 3}\left(-l_{\text {cor }}\right) \\
-u_{x, 4}\left(l_{\text {cor }}\right) & u_{z, 4}\left(l_{\text {cor }}\right)
\end{array}\right) \cdot\left(\begin{array}{l}
\sin (\alpha) \\
\cos (\alpha)
\end{array}\right),
$$

where $u_{z, n}$ and $u_{x, n}$ are respectively the vertical and the streamwise velocity in the $n$-th bins of each beam. This procedure relies on the assumption that the flow is uniform in the horizontal plane ${ }^{23}$ :

$$
u_{i, 3}\left(-l_{\text {cor }}\right)=u_{i, 4}\left(l_{\text {cor }}\right)
$$

The streamwise velocity at deph $h$ thus reads $u_{x}=\left(u_{r, 3}-u_{r, 4}\right) / 2 \sin (\alpha)$. Similarly, beam 1 and beam 2 provide the transverse velocity $u_{y}{ }^{24}$.

The uniformity assumption proves reasonable to measure integrated quantities, such as the river discharge, or large flow structures. However, due to the large tilt angle $\alpha$ of a beam, the correlation length $l_{\text {cor }}$ is of the order of the flow depth (equation 1, figure 1). Therefore, 

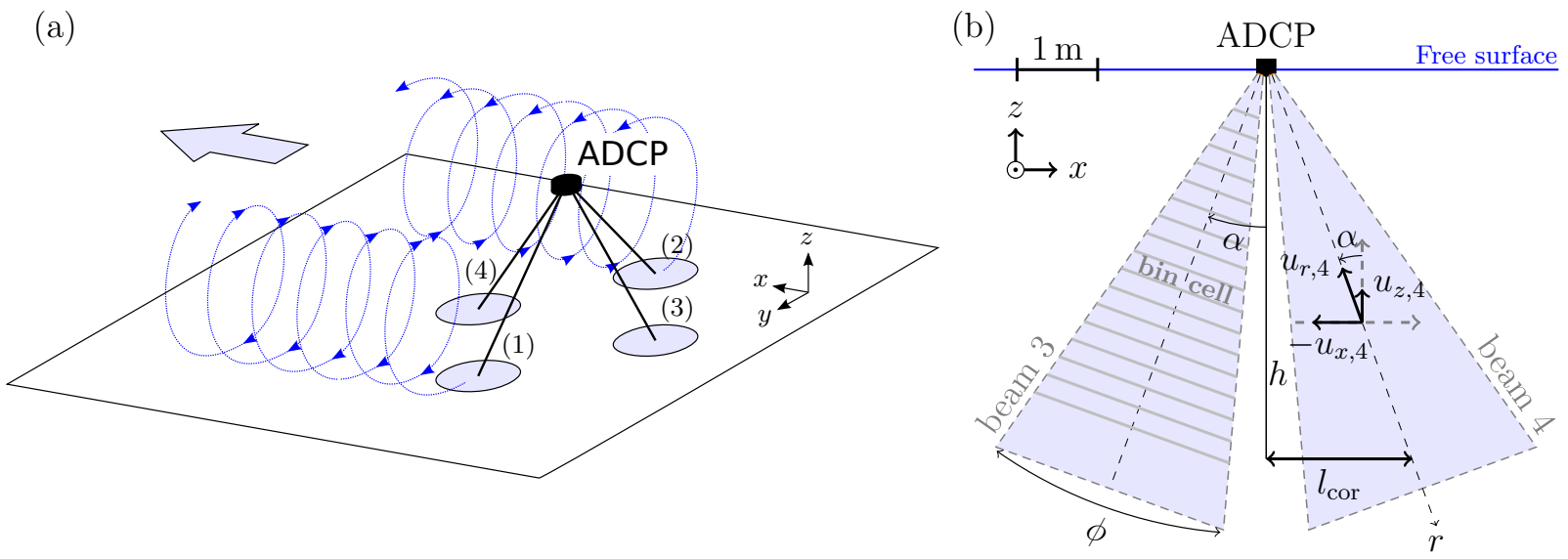

FIG. 1. (a) Configuration of the ADCP beams, oriented with respect to the primary flow. (b) Configuration of beams 4 and 3, in the vertical streamwise plane. The tilt angle of the beam is $\alpha=20^{\circ}$ and its opening angle is $\phi=30^{\circ}$. The radial velocity is measured at depth $h$. The associated correlation length is $l_{\text {cor }}$.

it cannot detect flow patterns smaller than the flow depth ${ }^{22}$. This precludes ADCPs from measuring the complete velocity field associated to secondary flow cells in a river.

In a straight channel however, we expect the average flow to be uniform in the streamwise direction, even in the presence of stationary helicoidal cells. The uniformity assumption therefore holds along the primary flow and, in principle, we can calculate the vertical velocity of secondary flow cells from the two acoustic beams aligned with the flow (beam 3 and beam 4 in figure $1 \mathrm{a})^{25,26}$.

Secondary flow cells are weak stationary eddies in a highly turbulent flow. We thus need to average the velocity field over time to reveal them. In addition, since the uniformity assumption holds only on average, our experimental setup can only measure the average velocity field in the vertical streamwise plane $(x, z)$. We define the average velocity as

$$
\overline{u_{i}}=\frac{1}{T} \int_{0}^{T} u_{i} \mathrm{~d} t
$$

where $i$ denotes the coordinate $x$ or $z$, and $T$ is a time period long enough to average out the unsteady turbulent flow ( $T \approx 10 \mathrm{~min}$ ). Fortunately, $\overline{u_{x}}$ and $\overline{u_{z}}$ suffice to identify secondary flow cells, and to estimate their influence on the flow. 


\section{B. Field site}

We collected our measurements midway of a $3 \mathrm{~km}$-long straight reach of the Seine river (France). The river flows above bedrock between two vertical banks (width: $148 \mathrm{~m}$, depth: about $6.2 \pm 0.3 \mathrm{~m}$ depending on the discharge, figure $2 \mathrm{a}$ ). The ADCP was mounted on a raft moored to a suspension footbridge which does not perturb the flow (figure $2 \mathrm{~b}$ ). The horizontal velocity of the raft was recorded by an echo-sounder, and the measurements are corrected for it. The raft position was measured with an auto-tracking theodolite with a precision of about a centimeter. We also used the ADCP goniometer to correct the measurements for the angular motion of the raft.
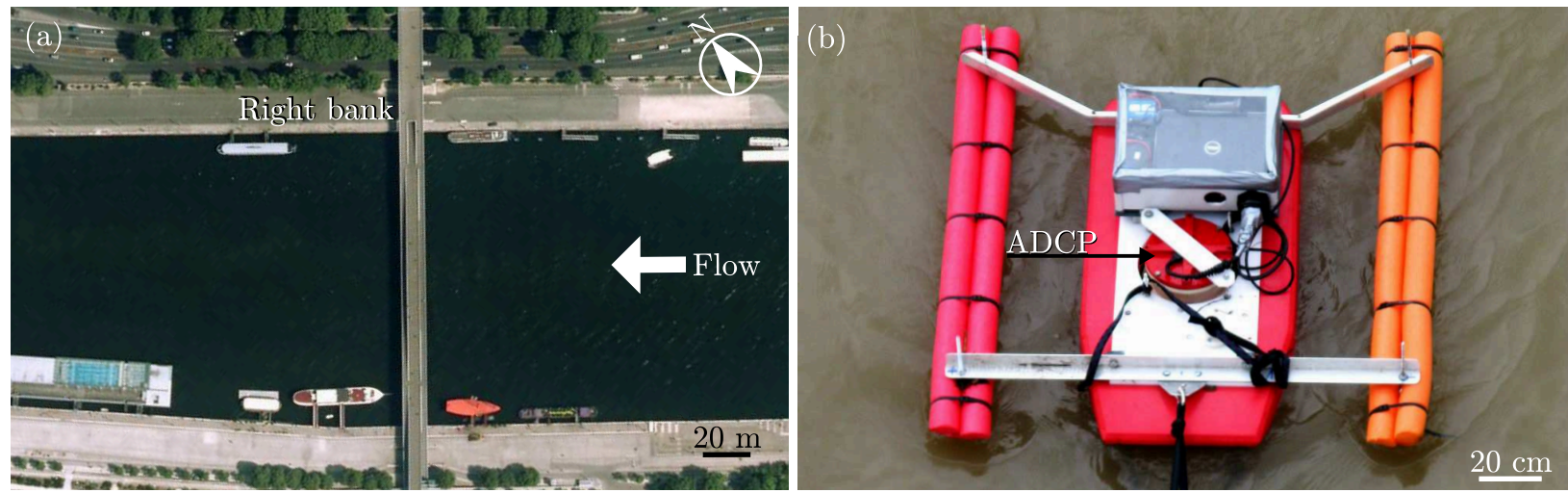

FIG. 2. (a) Aerial picture of the field site (source: Institut Géographique National). Measurements are made from the footbridge. (b) Set-up of the measurement raft.

We acquired three data sets at the same location and at comparable discharges (January 2011: $900 \mathrm{~m}^{3} \mathrm{~s}^{-1}$, February 2012: $950 \mathrm{~m}^{3} \mathrm{~s}^{-1}$, February 2013: $780 \mathrm{~m}^{3} \mathrm{~s}^{-1}$ ). For each set, we collected static measurements across the river, about $2 \mathrm{~m}$ apart from each other. Each static measurement lasted about 10 min, a duration sufficient for the turbulent component of the flow to average out. In addition, we collected measurements in a transect by slowly pulling the raft along the footbridge. 


\section{OBSERVATIONS}

\section{A. Streamwise velocity}

To visualize the primary flow, we define the depth-averaged streamwise velocity as

$$
U_{x}(y)=\frac{1}{H} \int_{0}^{H} \overline{u_{x}} \mathrm{~d} z
$$

where $H$ is the water depth. The primary velocity appears roughly constant around the center of the channel, and slows down near the banks (figure 3a). As a result, the velocity profile is curved over about two thirds of the river width. Since the water depth is virtually constant across the river, this profile suggests that the flow transfers streamwise momentum to the banks.

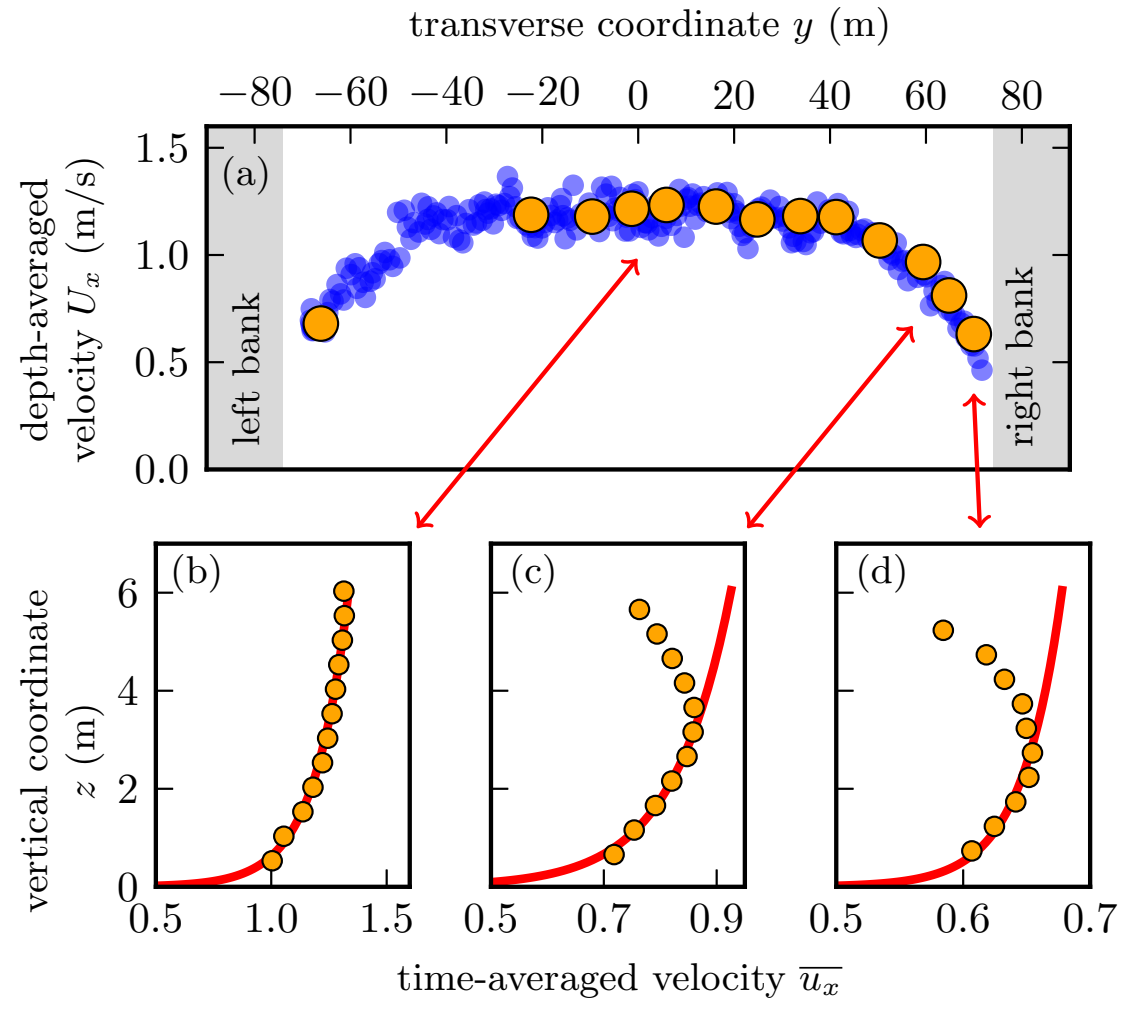

FIG. 3. Streamwise velocity measurements $\left(\mathrm{m} . \mathrm{s}^{-1}\right)$ in the Seine river during winter high flow. The discharge is $900 \mathrm{~m}^{3} / \mathrm{s}$. (a) Depth-averaged velocity $U_{x}$ from moving measurements (blue) and from static measurements (yellow). (b), (c), (d) Time-averaged ( $\simeq 10$ minutes) depth profiles $\left(\overline{u_{x}}\right)$ with fitted logarithmic profiles (red curve).

The vertical velocity profile is also affected by the banks. At the center of the channel, 
the velocity profile resemble the classical logarithmic law of the wall (figure 3b). However, as we approach the banks, the vertical profile deforms: the point of maximum velocity detaches from the water surface and migrates downwards, until it reaches approximately half the flow depth (figure 3c-d).

This observation is reminiscent of laboratory experiments showing a velocity maximum at about $z=0.6 H$ near the banks ${ }^{10,27}$. This departure from the logarithmic profile is usually

interpreted as a signature of secondary flow cells near duct corners ${ }^{7,10,11}$ : these cells create an upward velocity along the side wall, thus bringing slow fluid up to the surface. The center of the cell, hardly impacted by the cell velocity, flows faster than the surrounding fluid. The same flow cell would have a much weaker effect far away from the banks, since the slow water must be transported from the bottom to the surface, thus explaining why the profiles near the center and near the bank differ.

Similarly, the weak spatial oscillation of the streamwise velocity across the river suggests that periodic upwelling brings slow water from the bottom to the surface (figure $3 \mathrm{a}$ ).

\section{B. Vertical velocity}

The streamwise velocity profiles suggests that secondary flow cells exist across the entire channel. We now turn our attention to the vertical velocity, which provides direct insight on such flow structures (figure 4).

To reduce the scatter, the data set is divided into $2 \mathrm{~m}$-wide bins. The vertical velocity is then averaged over each bin, and the standard deviation within a single bin provides an estimate of the error on the mean. The mean vertical velocity shows periodic oscillations across the river, with an amplitude significantly larger than the measurement error. As expected, the average vertical velocity across the channel vanishes, indicating that the vertical motion of the raft does not perturb significantly the measurements.

Despite considerable scatter, both the amplitude and the wavelength of this oscillation are roughly constant over the right-hand half of the river (the duration of the high-flow conditions did not allow measurements across the entire channel). They also show a reasonable consistency between data sets collected one year apart.

Fitting a cosine to the data leads to a wavelength of about $12 \pm 0.5 \mathrm{~m}$, and an amplitude of about $0.4 \pm 0.1 \mathrm{~cm} \mathrm{~s}^{-1}$. The Fourier spectrum of the same data set shows a maximum at 


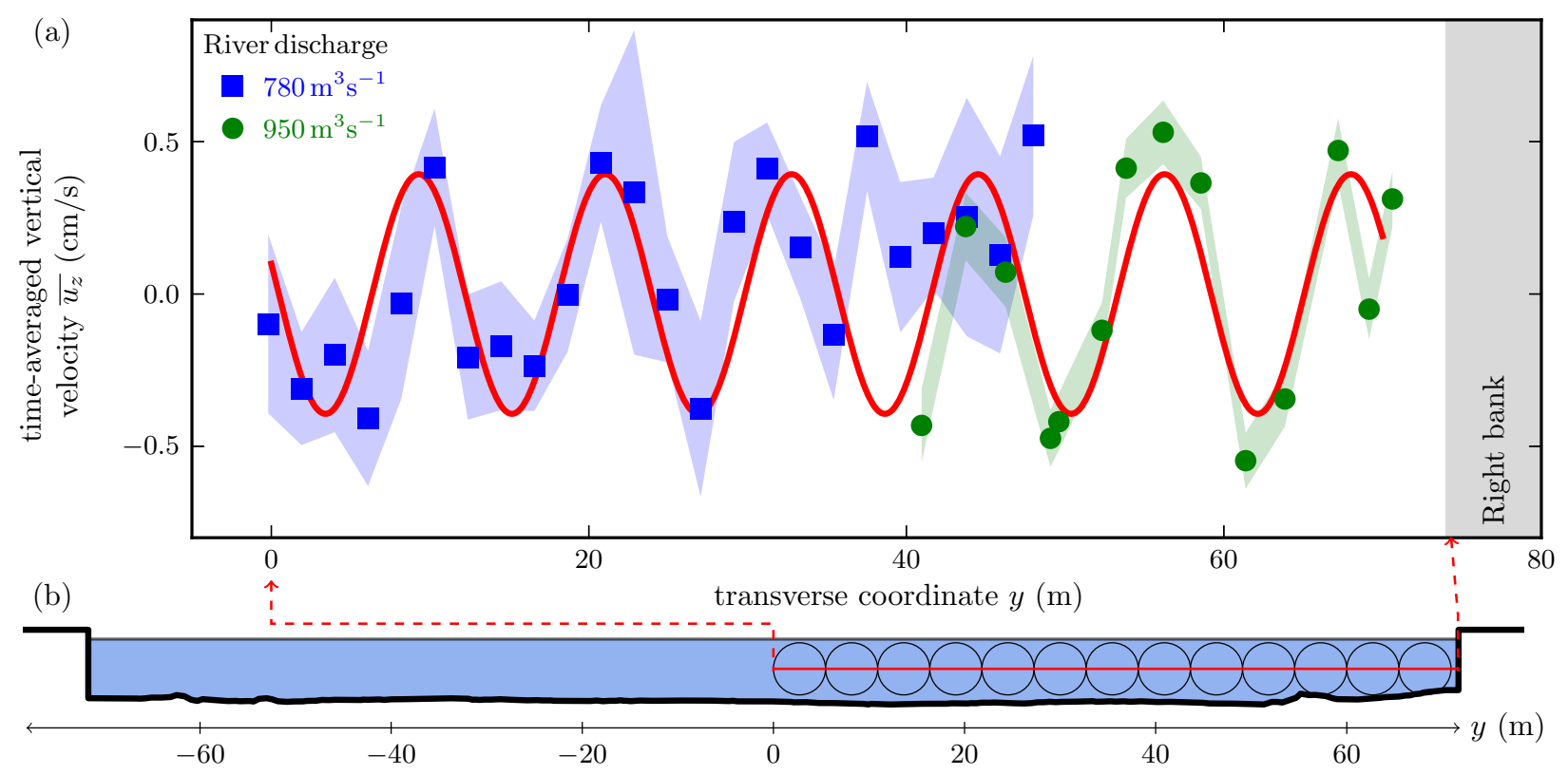

FIG. 4. (a) Time-averaged vertical velocity $\overline{u_{z}}$ in a transect, at half the flow depth. The shaded envelopes represent the standard error on the mean. The red curve is a cosine fitted to the data. (b) Topography of the river cross-section at the measurement location (scales are preserved). The distance $y$ is measured from the middle of the channel.

a wavelength of about $12 \pm 0.5 \mathrm{~m}$ (figure 5). Based on this observation, and in accordance with previous experiments ${ }^{7,8}$, we suggest that the flow generates recirculation cells across the entire channel. The wavelength of the velocity oscillation corresponds to a series of counterrotating vortices with a diameter of about the flow depth (figure $4 \mathrm{~b}$ and figure 6 ). The amplitude of the vertical oscillation is about $0.3 \%$ of the streamwise velocity, in accordance with previous findings in laboratory flumes ${ }^{7}$.

\section{MOMENTUM TRANSFER BY RECIRCULATION CELLS}

In this section, our intention is to quantify the contribution of secondary flow cells in transporting momentum across the flow. To do so, we use a heuristic model to include the advection by secondary flow cells in the streamwise momentum balance. 


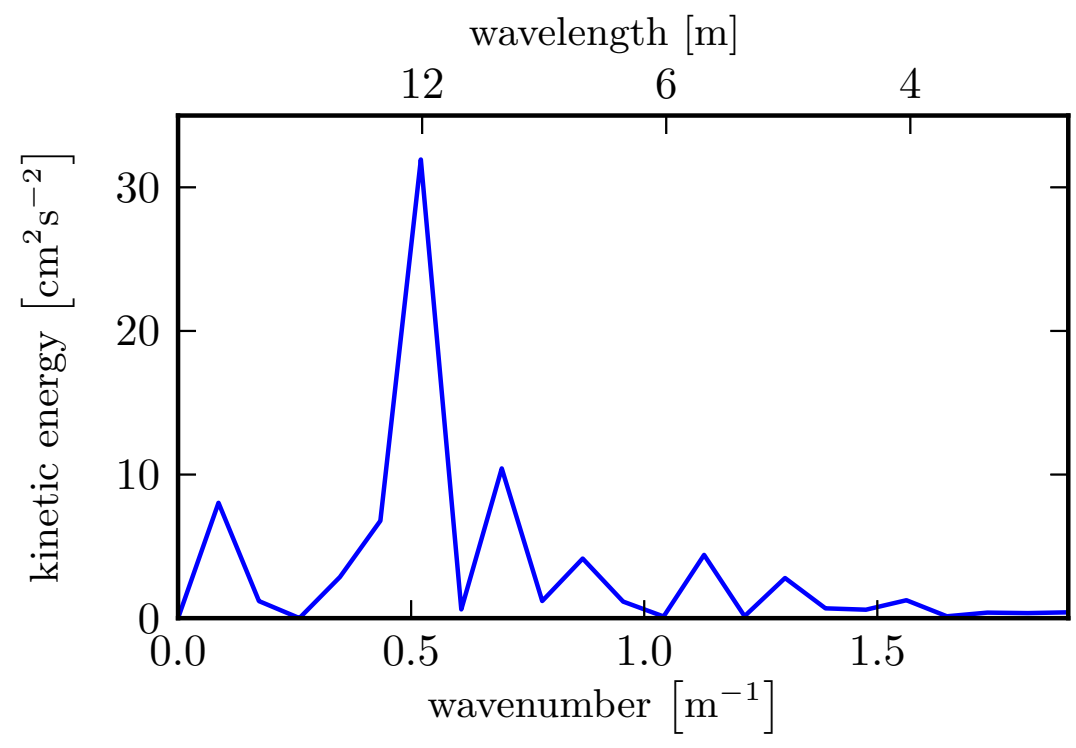

FIG. 5. Energy spectrum of the vertical velocity field, calculated from the data set of figure 4 .

\section{A. Momentum balance}

In steady state, the Reynolds-averaged Navier-Stokes equation for streamwise momentum reads

$$
\rho \frac{\partial\left\langle u_{j}\right\rangle\left\langle u_{x}\right\rangle}{\partial x_{j}}=\frac{\partial \tau_{x, j}}{\partial x_{j}}+\rho g S
$$

where $g, S$ and $\rho$ are the acceleration of gravity, the river slope and the density of water respectively. The repeated $j$ index implies summation over the transverse $y$ and vertical $z$ coordinates. The brackets denote ensemble average and $\tau_{x, j}$ is the stress tensor, including the Reynolds components.

In a rectangular channel with a steady free surface, the integration of equation (6) over depth leads to

$$
\frac{\partial}{\partial y} \int_{0}^{H}\left(\rho\left\langle u_{x}\right\rangle\left\langle u_{y}\right\rangle-\tau_{y, x}\right) \mathrm{d} z=-\tau_{\text {bottom }}+\rho g H S .
$$

In the above equation, the left-hand term represents the cross-stream momentum transfer by the conjugate action of the secondary flow and turbulence ${ }^{9}$. Even though the two integrands $\rho\left\langle u_{x}\right\rangle\left\langle u_{y}\right\rangle$ and $\tau_{y, x}$ can be isolated formally, they are physically interdependent.

The bottom shear stress $\tau_{\text {bottom }}$ is often empirically approximated by a friction law:

$$
\tau_{\text {bottom }} \approx \rho C_{f} U^{2}
$$

where $U$ is the mean velocity and $C_{f}$ is a friction coefficient. 


\section{B. Turbulent transfer of momentum}

We first consider the contribution of turbulence to the cross-stream transfer of momentum. Discarding temporarily the influence of the secondary flow, we use an empirical eddy viscosity $\nu_{t}$ to get a rough estimate of the turbulent transfer:

$$
\tau_{x, y} \approx \rho \nu_{t} \frac{\partial\left\langle u_{x}\right\rangle}{\partial y}
$$

Based on laboratory and field measurements, the vertical profile of eddy viscosity in an open channel is often approximated by a parabola ${ }^{10,28-30}$ :

$$
\nu_{t} \equiv \kappa u_{\star} z\left(1-\frac{z}{H}\right)
$$

where $\kappa$ is the von Kármán constant and $u_{\star}$ is the friction velocity defined as $\rho u_{\star}^{2}=\tau_{\text {bottom }}$.

In an infinitely wide channel (that is, without any flux of momentum across the stream), the velocity profile resulting from equation (6) with a turbulent viscosity closure (10) is logarithmic:

$$
\left\langle u_{x}\right\rangle=\frac{u_{\star}}{\kappa} \ln \left(\frac{z}{z_{0}}\right)
$$

where $z_{0}$ is the roughness length.

In a bounded channel, on the other hand, momentum is transferred from the flow bulk to the banks and, strictly speaking, equation (11) does not hold. However, if the channel aspect ratio is sufficiently large, we may assume that the vertical velocity profile remains logarithmic, in tune with the classical shallow-water approximation:

$$
\left\langle u_{x}\right\rangle=U(y) \frac{\sqrt{C_{f}}}{\kappa} \ln \left(\frac{z}{z_{0}}\right),
$$

where $U(y)$ is the depth-averaged velocity.

Based on equations (9) and (12), the cross-stream flux of momentum associated to the Reynolds stress tensor then reads

$$
\int_{0}^{H} \tau_{x, y} \mathrm{~d} z \approx \mathcal{B} C_{f} H^{2} U \frac{\partial U}{\partial y}
$$

where $\mathcal{B}$ depends on the ratio of the water depth to the roughness length only:

$$
\mathcal{B}=\frac{1}{6} \ln \left(\frac{H}{z_{0}}\right)-\frac{5}{36} .
$$




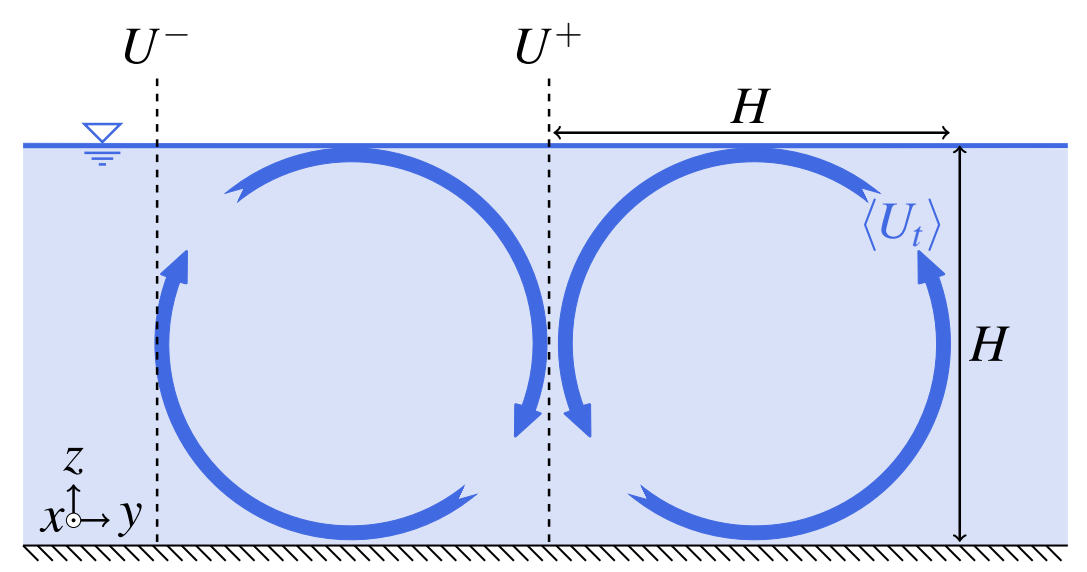

FIG. 6. Schematic representation of the recirculation cells.

Using the above expression to model the cross-stream momentum transfer, the momentum balance (7) reads

$$
g H S=C_{f} U^{2}-\frac{\mathcal{B} C_{f} H^{2}}{2} \frac{\partial^{2} U^{2}}{\partial y^{2}}
$$

To evaluate $\mathcal{B}$ from equation (14), we need an estimate of the roughness length $z_{0}$. Fitting a logarithm on several vertical velocity profiles near the center of the Seine river (figure $3 \mathrm{~b}$ ), we find an average value of $z_{0} \approx 2 \pm 1 \mathrm{~mm}$ (this value is comparable with prior field measurements ${ }^{31}$ ), and therefore $\mathcal{B} \approx 1.2 \pm 0.1$.

\section{Influence of the the secondary flow on the momentum transfer}

We now consider the influence of the secondary flow on the cross-stream transfer of momentum. Based on both the fluctuation of the vertical velocity across the stream (figure 4), and mass balance, we expect the recirculation cells to be arranged in a series of counterrotating eddies, with a diameter of about the water depth and a velocity $\left\langle U_{t}\right\rangle$ (figure 6). Such a flow configuration, by itself, cannot transfer momentum beyond one cell diameter, as it is compartmented by vertical planes of vanishing cross-stream velocity. However, turbulent diffusion can take over the momentum transfer across these vertical planes, where the momentum gradient is enhanced by the recirculation cells. The mixing due to counter-rotating eddies could thus increase the diffusion of momentum across the stream ${ }^{32}$.

Assuming that the momentum transfer is limited by convection within the cells, we expect it to scale like $\rho H\left\langle U_{t}\right\rangle\left(U^{-}-U^{+}\right)$where $U^{-}$and $U^{+}$stand for the streamwise velocity left and right of a cell, respectively (figure 6). If the streamwise velocity varies on scales much 
larger than the water depth, we can approximate the velocity difference across a cell by a gradient, namely $U^{-}-U^{+} \approx H \partial U / \partial y$. This approximation is valid only in channels much larger than their depth, which is usually true for alluvial rivers ${ }^{18}$.

Finally, based on prior experimental observations ${ }^{7,10}$ and on the measurements presented in section III, we assume that the velocity of the secondary flow scales like that of the primary flow:

$$
\left\langle U_{t}\right\rangle \approx C_{d} U(y)
$$

where $C_{d} \approx 0.003 \pm 0.001$. The momentum balance then reads

$$
g H S=C_{f} U^{2}-\frac{C_{d} H^{2}}{2} \frac{\partial^{2} U^{2}}{\partial y^{2}}
$$

This expression is similar to equation (15), except the dimensionless coefficient $C_{d}$ is substituted for $\mathcal{B} C_{f}$.

\section{Comparison with field data}

We now proceed to compare the estimates of the cross-stream flux of momentum to our field measurements in the Seine river. Equations (15) and (17), with the requirement that the velocity vanishes at the banks, share the following analytical solution:

$$
U_{x}=U_{\infty} \sqrt{1-\frac{\cosh \left(y / L_{t}\right)}{\cosh \left(w /\left(2 L_{t}\right)\right)}},
$$

where

$$
U_{\infty}=\sqrt{\frac{g H S}{C_{f}}} .
$$

The diffusion length $L_{t}$ determines the inflection of the velocity profile near the banks. Its mathematical expression depends on the cross-stream diffusion model:

$$
\begin{gathered}
L_{t}=H \sqrt{\frac{\mathcal{B}}{2}} \quad(\text { no secondary flow, equation }(15)) \\
\left.L_{t}=H \sqrt{\frac{C_{d}}{2 C_{f}}} \quad \text { (with secondary flow, equation }(17)\right) .
\end{gathered}
$$

We evaluate the parameters $U_{\infty} \approx 1.2 \mathrm{~m} \mathrm{~s}^{-1}$ and $L_{t} \approx 14 \mathrm{~m}$ by fitting equation (18) to the data (figure 7). The resulting shape of the velocity profile accords reasonably with the data. 


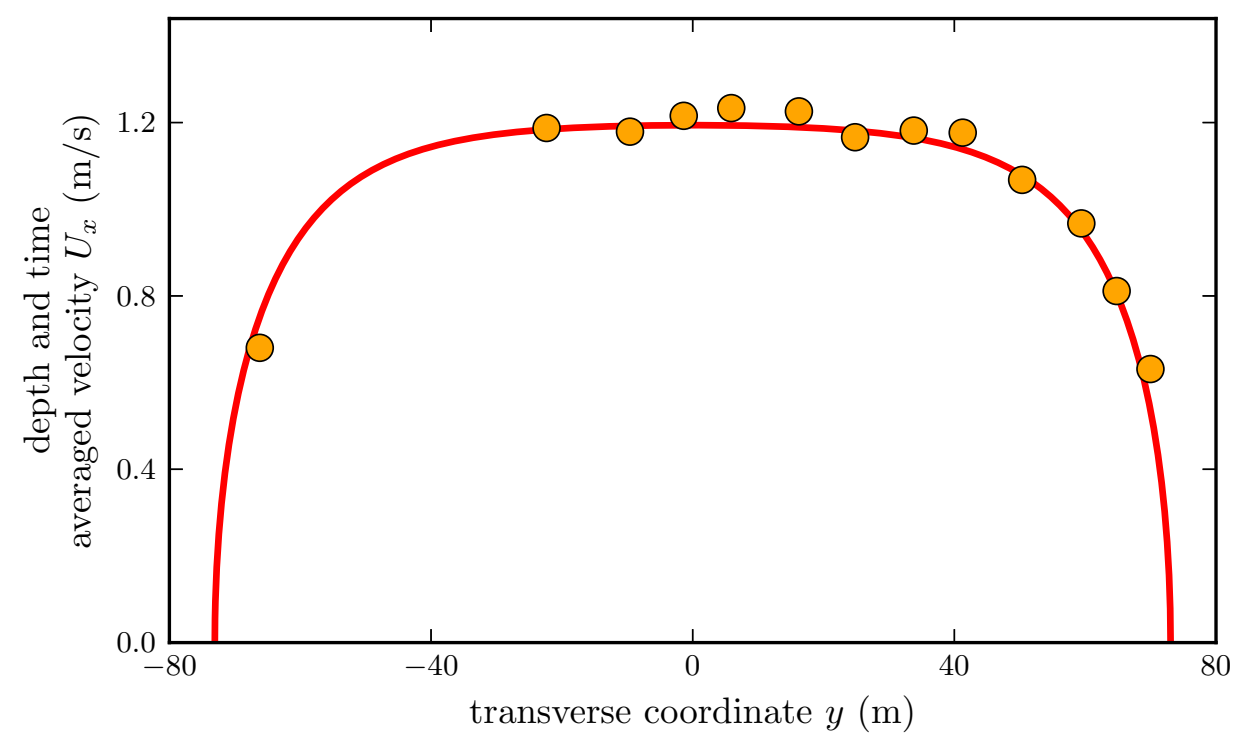

FIG. 7. Comparison of the depth-averaged momentum balance (red curve) with the ADCP measurements (yellow dots). Equation (18) is represented with $U_{\infty} \approx 1.2 \mathrm{~m} \mathrm{~s}^{-1}$ and $L_{t} \approx 14 \mathrm{~m}$ fitted to the data.

Since the the slope of the Seine river in Paris is about $10^{-4}$, we find $C_{f} \approx 0.0042 \pm 0.0001$, which is consistent with classical empirical formulas ${ }^{33,34}$. The estimation of $U_{\infty}$, and therefore of $C_{f}$, is virtually independent from the value of the diffusion length $L_{t}$.

Based on our estimate of $C_{f}$ and on relations (20) and (21), we can calculate the diffusion length for the two diffusion models:

$$
\begin{aligned}
& L_{t} \approx 4.8 \pm 0.1 \mathrm{~m} \quad \text { (no secondary flow) } \\
& L_{t} \approx 3.7 \pm 0.6 \mathrm{~m} \quad \text { (with secondary flow) }
\end{aligned}
$$

The estimated diffusion length is similar for both models, and about three times smaller than the fitted value. Therefore, the two diffusion models not only share the same mathematical expression (equations (15) and (17)), but also involve similar constants. We thus expect the turbulent transfer of momentum to be comparable with the transfer induced by the secondary flow.

The similarity between the two transfer mechanisms implies (i) that recirculation cells cannot be neglected in the momentum balance, and (ii) that the momentum transfer by the recirculation cells cannot be distinguished from the turbulent transfer in the shallow-water framework presented here. 


\section{DISCUSSION AND CONCLUSION}

Due to the diverging configuration of its acoustic beams, an ADCP generally cannot detect flow structures smaller than the flow depth. However, if the measurements are averaged over a sufficient period of time, this instrument can measure stationary and spatially extended flow structures.

We can unambiguously identify secondary flow cells in the vertical velocity field of the Seine River. These stationary vortices extend across the entire channel and rotate at about $0.3 \%$ of the streamwise velocity, in accord with prior laboratory observations ${ }^{6,7}$.

An order-of-magnitude analysis suggests that the momentum transfer by these secondary flow cells could compare with the intensity of the turbulent stress. If confirmed, this would indicate that the secondary flow influences significantly the primary flow in open channels. This is a strong incentive for further investigations. For instance, detailed flow measurements in laboratory experiments could reveal the streamwise extension of the flow cells, their stability in time and how they depend on the Reynolds number. Experiments would also guide us towards the mechanism which generates these structures.

In rivers, the momentum distribution determines stress on the bed, and therefore controls sediment transport and bed erosion. In addition, secondary cells are likely to enhance the horizontal mixing of passive markers, such as suspended particles, temperature or solutes ${ }^{35}$.

Finally, beyond open-channel flows, similar recirculation cells appear in a variety of turbulent sheared flows, such as longitudinal streaks in boundary layers ${ }^{36,37}$, Langmuir circulations below the wind-blown surface of lakes and oceans ${ }^{38}$, or even granular flows ${ }^{39}$. To this day, we do not know how many of these phenomena share a common physical origin, if any.

\section{ACKNOWLEDGMENTS}

The authors would like to thank the Navigation Service of the Seine river, represented by X. Fromageau, who granted access to the field site. A. Vierra built the measurement set-up. We also thank M. Rossi, P.Y. Lagrée and F. Moisy for fruitful discussions. 


\section{REFERENCES}

${ }^{1}$ Y. Forterre and O. Pouliquen, "Stability analysis of rapid granular chute flows: formation of longitudinal vortices," Journal of Fluid Mechanics 467, 361-387 (2002).

${ }^{2}$ H. Pabiou, S. Mergui, and C. Benard, "Wavy secondary instability of longitudinal rolls in Rayleigh-Bénard-Poiseuille flows," Journal of Fluid Mechanics 542, 175-194 (2005).

${ }^{3} \mathrm{H}$. Jeffreys, "On the transverse circulation in streams," in Mathematical Proceedings of the Cambridge Philosophical Society, Vol. 25 (Cambridge Univ Press, 1929) pp. 20-25.

${ }^{4}$ J. Znaien, Y. Hallez, F. Moisy, J. Magnaudet, J. P. Hulin, D. Salin, and E. J. Hinch, "Experimental and numerical investigations of flow structure and momentum transport in a turbulent buoyancy-driven flow inside a tilted tube," Physics of Fluids 21, 115102-115102 (2009).

${ }^{5}$ Y. Hallez and J. Magnaudet, "Turbulence-induced secondary motion in a buoyancy-driven flow in a circular pipe," Physics of Fluids 21, 081704 (2009).

${ }^{6} \mathrm{~J}$. Rodriguez and M. Garcia, "Laboratory measurements of 3-d flow patterns and turbulence in straight open channel with rough bed," Journal of Hydraulic Research 46, 454-465 (2008).

${ }^{7}$ K. Blanckaert, A. Duarte, and A. J. Schleiss, "Influence of shallowness, bank inclination and bank roughness on the variability of flow patterns and boundary shear stress due to secondary currents in straight open-channels," Advances in Water Resources 33 (2010).

${ }^{8}$ I. Albayrak and U. Lemmin, "Secondary currents and corresponding surface velocity patterns in a turbulent open-channel flow over a rough bed," Journal of Hydraulic Engineering 137, 1318-1334 (2011).

${ }^{9} \mathrm{~K}$. Shiono and D. Knight, "Turbulent open-channel flows with variable depth across the channel," Journal of Fluid Mechanics 222, 617-646 (1991).

${ }^{10}$ I. Nezu and H. Nakagawa, Turbulence in Open-Channel Flows, IAHR Monographs (A.A. Balkema, 1993).

${ }^{11}$ L. Prandtl, Essentials of fluid dynamics: With applications to hydraulics aeronautics, meteorology, and other subjects (Blackie \& SON, 1952).

${ }^{12} \mathrm{E}$. Brundrett and W. Baines, "The production and diffusion of vorticity in duct flow," Journal of Fluid Mechanics 19, 375-394 (1963).

${ }^{13}$ B. Galletti and A. Bottaro, "Large-scale secondary structures in duct flow," Journal of 
Fluid Mechanics 512, 85-94 (2004).

${ }^{14}$ H. Einstein and H. Li, "Secondary currents in straight channels," Trans. Am. Geophys. Union 39, 1085-1088 (1958).

${ }^{15}$ F. Gessner, "The origin of secondary flow in turbulent flow along a corner," Journal of Fluid Mechanics 58, 1-25 (1973).

${ }^{16}$ A. Demuren, "Calculation of turbulence-driven secondary motion in ducts with arbitrary cross section," AIAA journal 29, 531-537 (1991).

${ }^{17}$ A. Husser and S. Biringen, "Direct numerical simulation of turbulent flow in a square duct," J. Fluid Mech 257, 65-95 (1993).

${ }^{18}$ F. Metivier and L. Barrier, "Alluvial landscape evolution: what do we know about metamorphosis of gravel bed meandering and braided streams," in Gravel-bed Rivers: processes, tools, environments., edited by M. Church, P. Biron, and A. Roy (Wiley \& Sons, Chichester, 2012) Chap. 34, pp. 474-501.

${ }^{19}$ S. Ikeda, "Self-formed straight channels in sandy beds," Journal of the Hydraulics Division 107 (1981).

${ }^{20}$ M. Colombini and G. Parker, "Longitudinal streaks," Journal of Fluid Mechanics 304, 161-184 (1995).

${ }^{21} \mathrm{~V}$. Vanoni, Experiments on the transportation of suspended sediments by water, Ph.D. thesis, California Institut of Technology (1940).

${ }^{22}$ A. Gargett, "Observing turbulence with a modified acoustic doppler current profiler," Journal of Atmospheric and Oceanic Technology 11, 1592 (1994).

${ }^{23}$ R. Gordon, "Principles of operation a practical primer," Tech. Rep. (RD Instruments, 1996).

${ }^{24} \mathrm{RD}$ Instruments, "ADCP coordinate transformation-formulas and calculations: RD Instruments," Tech. Rep. (N 951-6079-00, 1998).

${ }^{25}$ M. Stacey, S. Monismith, and J. Burau, "Measurements of reynolds stress profiles in unstratified tidal flow," Journal of Geophysical Research 104, 10933-10 (1999).

${ }^{26}$ E. Nystrom, C. Rehmann, and K. Oberg, "Evaluation of mean velocity and turbulence measurements with ADCPs," Journal of hydraulic engineering 133, 1310 (2007).

${ }^{27}$ A. Gibson, "On the depression of the filament of maximum velocity in a stream flowing through an open channel," Proceedings of the Royal Society of London. Series A 82, 149-159 (1909). 
${ }^{28}$ D. A. Lyn, Sedimentation Engineering: Processes, Measurements, Modeling, and Practice (2008) pp. 763-826.

${ }^{29}$ J.-M. Hervouet, Hydrodynamics of Free Surface Flows: Modelling with the finite element method (Wiley Online Library, 2007).

${ }^{30}$ I. Nezu and W. Rodi, "Open-channel flow measurements with a laser doppler anemometer," Journal of Hydraulic Engineering 112, 335-355 (1986).

${ }^{31}$ M. H. García, "Sedimentation engineering: processes, measurements, modeling, and practice," (ASCE Publications, 2008) Chap. 2.2, pp. 24-34.

${ }^{32}$ B. Audoly, H. Berestycki, and Y. Pomeau, "Réaction diffusion en écoulement stationnaire rapide," Comptes Rendus de l'Academie des Sciences Series IIB Mechanics Physics Astronomy 328, 255-262 (2000).

${ }^{33}$ A. Chezy, "Formule pour trouver la vitesse de l'eau conduite dans une rigole donnée." in Annales des Ponts et Chaussées, Vol. 61 (1776) pp. 165-269.

${ }^{34}$ M. S. Yalin and A. M. Ferreira da Silva, Fluvial Processes (International Association of Hydraulic Engineering and Research Monograph, 2001) p. 197.

${ }^{35}$ J. Bouchez, E. Lajeunesse, J. Gaillardet, C. France-Lanord, P. Dutra-Maia, and L. Maurice, "Turbulent mixing in the Amazon River: The isotopic memory of confluences," Earth and Planetary Science Letters 290, 37-43 (2010).

${ }^{36}$ G. Wanmin and P. A. Taylor, "Turbulent boundary-layer flow over fixed aerodynamically rough two-dimensional sinusoidal waves," J. Fluid Mech 312, 1-31 (1996).

${ }^{37}$ Y. Aihara, "Formation of longitudinal vortices in the sublayer due to boundary-layer turbulence," Journal of Fluid Mechanics 214, 111-129 (1990).

${ }^{38}$ I. Langmuir et al., "Surface motion of water induced by wind," Science 87, 119-123 (1938).

${ }^{39}$ Y. Forterre and O. Pouliquen, "Longitudinal vortices in granular flows," Physical Review Letters 86, 5886-5889 (2001). 